\title{
Penyebab Anak Stunting: Perspektif Ibu
}

\section{Causes of Child Stunting: A Mother's Perspective}

\author{
Erni Setiyowati ${ }^{1}$, Meivita Dewi Purnamasari ${ }^{2}$, Nina Setiawati ${ }^{3}$ \\ Fakultas Ilmu Kesehatan, Universitas Jenderal Soedirman, Indonesia
}

\section{ARTICLE INFO}

\section{Article history}

Received date

18 Dec 2020

Revised date

09 Mar 2021

03 Jun 2021

Accepted date

12 Jul 2021

Keywords:

Heredity;

Maternal experience;

Stunting.

\section{Kata kunci:}

Keturunan;

Penalaman ibu;

Stunting.

\begin{abstract}
ABSTRAK
Stunting is one of the health problems in Indonesia. The cause of stunting is inadequate intake of nutrients which will have an impact on physical growth, motor and mental development, as well as intelligence, socio-emotional values. Mothers who have stunted children experience different experiences. This causes different perceptions about the causes of stunting for mothers. This study uses a qualitative method with a phenomenological approach. The purpose of the study was to explore the experience of mothers caring for children who experience stunting. The research was conducted in Banyumas Regency. The informants involved were 15 mothers who had stunted children aged 25-60 months. The research resulted in one of the themes, namely the causes of stunting for mothers. The themes consist of heredity categories, difficult children/picky eaters, children's health conditions, and financial conditions. According to the informant, heredity is the main cause of stunting, so it is assumed that stunting cannot be prevented. This shows the need for adequate information for informants about the factors that cause stunting. Mothers need counseling and supervision to increase their knowledge and ability in caring for children, especially in meeting nutritional needs.
\end{abstract}

Stunting merupakan salah satu masalah kesehatan di Indonesia. Penyebab stunting adalah tidak adekuatnya asupan zat gizi yang akan berdampak pada pertumbuhan fisik, perkembangan motorik dan mental, serta nilai inteligensi, sosial-emosional. Ibu yang memiliki anak stunting mengalami pengalaman yang berbeda beda. Hal ini menyebabkan persepsi yang berbeda tentang penyebab stunting bagi ibu. Penelitian ini menggunakan metode kualitatif dengan pendekatan fenomenologi. Tujuan penelitian untuk menggali pengalaman ibu merawat anak yang mengalami stunting. Penelitian dilaksanakan di Kabupaten Banyumas. Informan yang terlibat sebanyak 15 orang ibu yang memiliki anak stunting usia 25-60 bulan. Penelitian menghasilkan salah satu tema yaitu penyebab anak stunting bagi ibu. Tema terdiri atas kategori keturunan, anak sulit/pemilih makanan, kondisi kesehatan anak, dan kondisi finansial. Menurut informan, keturunan merupakan penyebab utama terjadinya stunting sehingga memiliki anggapan stunting tidak dapat dicegah. Hal ini menunjukkan perlunya informasi yang adekuat bagi informan tentang factor yang menyebabkan stunting. Ibu memerlukan konseling dan supervisi untuk meningkatkan pengetahuan dan kemampuan dalam merawat anak khususnya dalam memenuhi kebutuhan nutrisi.

Corresponding Author:

Erni Setiyowati

Fakultas Ilmu Kesehatan, Universitas Jenderal Soedirman, Indonesia

Email: ernisetiyowati@unsoed.ac.id

\section{PENDAHULUAN}

Stunting menjadi prioritas kesehatan masyarakat dunia. Prevalensi stunting Indonesia lebih tinggi dari negara lain di Asia Tenggara (Paciorek CJ, Stevens GA, Finucane MM, et al., 2013). Riskesdas 2018 menunjukkan stunting
(TB/U) pada balita di Indonesia mencapai 30,8\%. Angka ini tidak merata pada semua provinsi yang ada di Indonesia (Kusrini \& Laksono, 2020). Persentase anak stunting di Jawa Tengah mencapai $28,5 \%$ pada kelompok balita. Salah satu Kabupaten yang ada di Jawa Tengah yaitu Kabupaten Banyumas, menunjukan angka 
stunting 24,5\% pada balita. Angka ini lebih tinggi dibandingkan pada kelompok baduta 14,6\% (Dinas Kesehatan Kabupaten Banyumas, 2018).

Stunting yang terjadi pada anak disebabkan berbagai faktor. Salah satunya yaitu tidak adekuatnya asupan zat gizi dan infeksi berulang serta penyakit kronis yang berlangsung pada seribu hari pertama kehidupan/HPK (Mahmudiono T, Nindya T, 2016). Pada masa kehamilan, janin akan melakukan reaksi penyesuaian meliputi perlambatan pertumbuhan dengan pengurangan jumlah dan pengembangan sel-sel tubuh termasuk sel otak dan organ tubuh seperti jantung, hati, pankreas, otot, dan ginjal jika asupan nutrisi pada ibu hamil tidak adekuat. Stunting akan berpengaruh pada terhambatnya pertumbuhan fisik, perkembangan motorik dan mental, menurunnya nilai inteligensi, sosialemosional serta memiliki konsekuensi jangka panjang peningkatan risiko penyakit metabolik di usia dewasa (Paciorek CJ, Stevens GA, Finucane MM, et al., 2013).

Pola perawatan kesehatan, pola pengasuhan, ketersediaan dan akses pangan, dan karakteristik keluarga merupakan faktor yang mempengaruhi kejadian stunting pada anak. Keluarga memiliki peranan yang penting dalam meningkatkan status kesehatan anak. Hal ini sesuai dengan filosofi keperawatan anak bahwa perawatan pada anak tidak dapat dipisahkan dari peran keluarganya yang dikenal dengan istilah family centered care (Bowden, V. R., \& Greenberg, 2010). Begitu pula dalam memberikan perawatan pada anak stunting. Keluarga menjadi pihak yang memerlukan intervensi untuk pencapaian penanggulangan stunting.

Pemerintah telah mengupayakan berbagai program untuk menjawab permasalahan stunting. Intervensi gizi spesifik dan gizi sensitif merupakan upaya pencegahan stunting yang dicanangkan oleh pemerintah. Intervensi spesifik berhubungan dengan intervensi kesehatan misalnya penyediaan suplementasi dan makanan tambahan. Intervensi sensitif merupakan intervensi non kesehatan, peningkatan ekonomi keluarga, akses dan pemanfaatan air bersih, sanitasi yang sangat dibutuhkan untuk mendukung perilaku higienis pribadi dan lingkungan (Darnton-Hill, 2015).

Penelitian mengenai stunting telah banyak dilakukan. Anak-anak dengan stunting menunjukkan adanya penurunan perkembangan fungsi kognitif (Alam, et al., 2020). Sedangkan penelitian mengenai faktor yang berhubungan dengan stunting menunjukkan ada hubungan antara usia ibu ( $p$-value $=0,048 ; \quad \mathrm{OR}=1,583)$ dengan pendapatan keluarga ( $p$-value $=0,010$; $\mathrm{OR}=1,803)$, komplikasi persalinan ( $p$ value $=0,008 ; \quad \mathrm{OR}=2,091)$, pemberian ASI Eksklusif (ASI) di usia 0-6 tahun ( $p$-value $=0,000$; $\mathrm{OR}=2,321$, pemberian ASI eksklusif dan MPASI diberikan kepada bayi sebelum 6 bulan (MPASI) usia 6 bulan sampai 2 tahun ( $p$ value $=0,002 ; \mathrm{OR}=2,037)$, dan riwayat rawat inap anak ( $p$-value $=0,008 ; \mathrm{OR}=2,055)$ terhadap status gizi anak (Rahayuwati, et al., 2019).

Penelitan tentang stunting banyak dilakukan terutama terkait faktor-faktor yang berhubungan dengan kejadian stunting dan akibat dari stunting. Sedangkan penelitian pada ibu sebagai pengasuh utama anak yang mengalami stunting belum banyak dilakukan. Oleh karena itu, dilakukan penelitian mengenai pengalaman ibu dalam merawat anak stunting di Kabupaten Banyumas sebagai salah satu Kabupaten dengan angka stunting melebihi batas yang ditetapkan WHO. Penelitian ini bertujuan untuk menggali pengalaman ibu selama merawat anak yang mengalami stunting.

\section{METODE}

Penelitian ini menggunakan metode kualitatif dengan pendekatan fenomenologi. Pengambilan data dilaksanakan pada bulan JuliSeptember 2020 di Puskesmas wilayah Kedung Banteng, Sumbang 1 dan Kembaran 1, Kabupaten Banyumas, Jawa Tengah. Penelitian melibatkan 15 orang ibu yang memiliki anak stunting.

Kriteria informan yang terlibat dalam penelitian ini yaitu ibu yang memiliki anak stunting usia 24-59 bulan, anak tidak memiliki penyakit konginetal dan penyakit berat lainnya. Proses pengumpulan data selesai setelah terjadi saturasi data dan telah memenuhi variasi karakteristik informan yaitu ibu yang berusia diantara 20-30 tahun dan lebih dari 30 tahun, ibu bekerja dan tidak bekerja, ibu dengan satu anak dan lebih dari satu anak, ibu dengan tingkat pendidikan Sekolah Dasar sampai dengan Perguruan Tinggi, tinggal bersama keluarga inti dan keluarga besar serta berpenghasilan di bawah Upah Minimun Regional (UMR) maupun di atas UMR.

Proses penelitian diawali dengan menghubungi informan dan menjelaskan maksud dari penelitian yang dilakukan. Peneliti melakukan pengukuran tinggi badan dan berat badan untuk memvalidasi status gizi anak. Selanjutnya pengambilan data dilakukan melalui wawancara mendalam dengan panduan 
wawancara semi berstruktur. Wawancara dilakukan hanya bersama peneliti dan informan dengan durasi 45-60 menit. Selama wawancara, peneliti juga melakukan observasi. Hasil wawancara dan observasi kemudian diinterpretasikan dan dianalisis. Analisis data yang dilakukan yaitu tematik konten analisis.

Kredibilitas data dijaga dengan mengkonfirmasi dan mengklarifikasi informasi yang disampaikan oleh informan mengenai pengalaman dalam merawat anak stunting. Hasil transkrip harus sesuai dengan maksud yang disampaikan oleh partisipan. Peneliti menjalin komunikasi beberapa kali sebelum wawancara untuk membangun hubungan saling percaya dan kenyamanan selama wawancara. Selain itu, peneliti juga membandingkan hasil dari berbagai sumber dan literature.

Penelitian ini telah lolos uji etik dari komisi etik penelitian FIKES Universitas Jenderal Soedirman dengan nomor surat lolos uji etik dengan Nomor. 150/EC/KEPK/VII/2020.

\section{HASIL}

Tabel 1. Karakteristik Informan

\begin{tabular}{lrr}
\hline \multicolumn{1}{c}{ Karakteristik } & n & \% \\
\hline Usia & & \\
20-30 tahun & 6 & 40 \\
$>30$ tahun & 9 & 60 \\
\hline Status pekerjaan & & \\
$\quad$ Bekerja & 4 & 27 \\
Tidak bekerja & 11 & 73 \\
\hline Jumlah anak & & \\
1 anak & 5 & 25 \\
2-3 anak & 10 & 50 \\
\hline Tipe keluarga & & \\
Extended family & 7 & 47 \\
Nuclear family & 8 & 53 \\
\hline Tingkat pendidikan & & \\
SD & 2 & 13 \\
SMP & 7 & 47 \\
SMA & 5 & 33 \\
Perguruan Tinggi & 1 & 7 \\
\hline
\end{tabular}

Sebagian besar informan berusia di atas 30 tahun, status pekerjaan ibu rumah tangga dan memiliki lebih dari 1 anak. Tingkat pendidikan informan sebagain besar Sekolah Menengah Pertama (SMP).

Hasil analisis dari transkrip menghasilkan tema "penyebab stunting bagi ibu". Tema ini terdiri atas kategori keturunan, anak sulit makan dan pemilih makanan, faktor kesehatan dan yang terakhir faktor finansial.
Hasil penelitian menunjukkan sembilan orang informan menyatakan bahwa penyebab stunting pada anaknya adalah faktor keturunan.

Beberapa hasil transkrip dari enam informan sebagai berikut:

'Saya pendek mbak, Rama-ne pada' (bapaknya juga), wajar ya anak pendek (tertawa)....” (P1)

“....Yang penting anaknya lincah, ndak sakit sakitan, Saya aja dulu kecil badannya kata Ibu Saya..." (P4)

"Badan saya kurus mbak, seperti mbak lihat ini, walaupun sudah nda kerja ya begini ini, kok anaknya besar, lha anake sapa? (tersenyum)..." (P9)

"rapapa, sehat wis inyong ra mikir aneh-aneh (saya tidak berpikir macam-macam)...memang pada' (dengan keluarga)..." (P10)

“keturunan biasa..." (P11)

"ndak sakit, vitamin itu ndak mau yang dikasih...yah pasrah saja memang kecil...tapi jangan dibilang kurang gizi...sakit hati rasanya..." $(P 3)$

Selain faktor keturunan, informan menyatakan anak merupakan tipe anak yang sulit untuk makan atau pemilih makanan.

"anaknya yang ngga mau maem. Itu tadi pagi aja ga mau sarapan” ( $P 2)$

"Pertama umur 6 bulan kan dicobain maem, mulutnya udah ditutup" (P3)

Informan menyatakan penyebab stunting lainnya yaitu kondisi kesehatan anak seperti lahir kurang bulan, berat badan lahir rendah dan riwayat perawatan di Rumah Sakit saat bayi.

“lahirnya kecil mbak, belum waktunya...” (P5)

"Waktu bayi sering dirawat di rumah sakit, itu darahnya kurang kata dokternya" (P6)

Selain kondisi di atas, masalah finansial keluarga yang termasuk ekonomi menengah ke bawah merupakan salah satu penyebab stunting pada anak.

"Kita kerja apa saja mbak, semua untuk anak, kalau ada yang semuanya..." (P12)

"Susu biasanya 1 kotak itu, apa kurang? langka koh'(tidak ada) ..."(tersenyum) (P15) 
Analisis tema yang dilakukan dari hasil transkrip sebagai berikut:

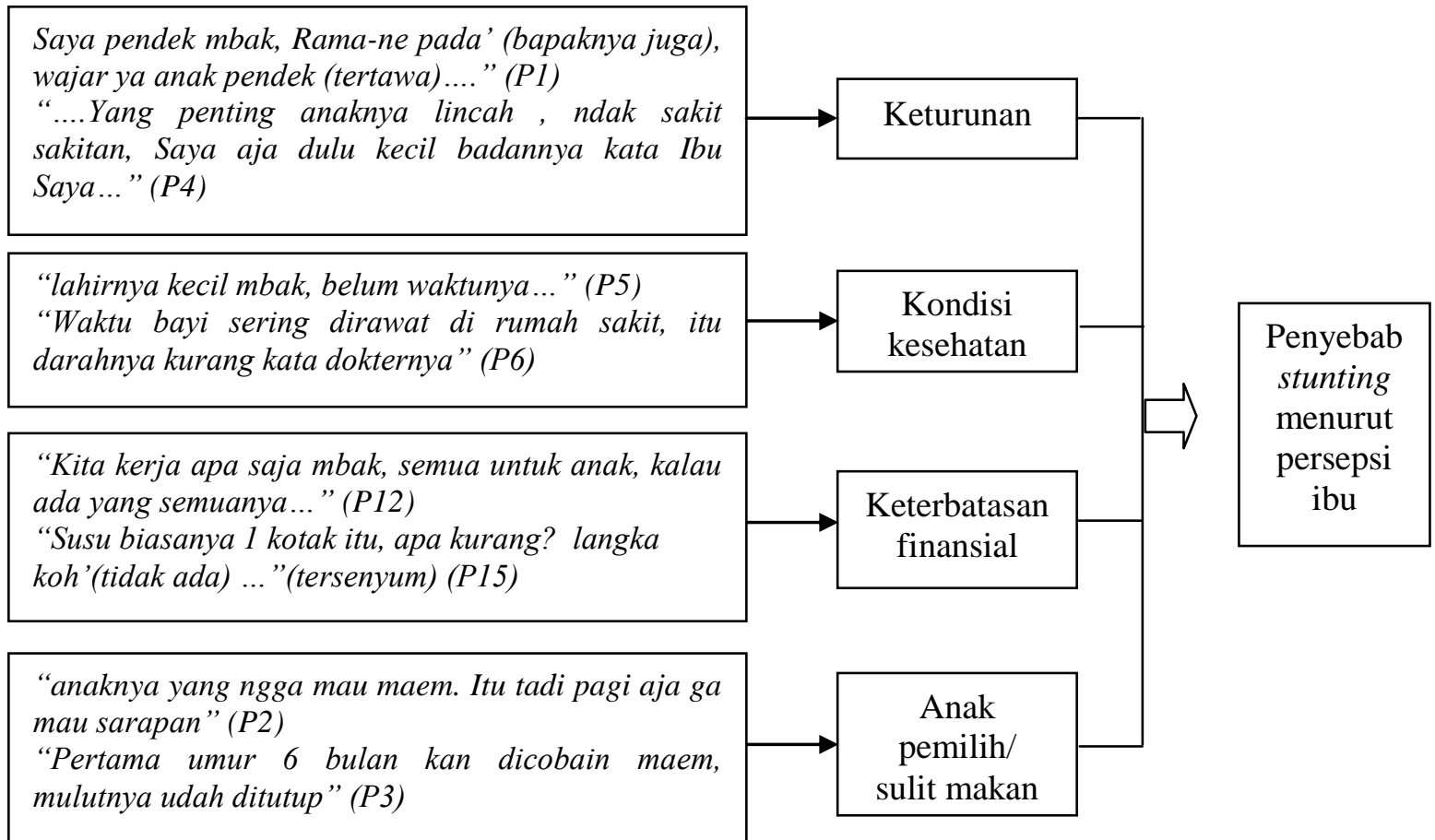

Gambar 1. Analisis Tema

\section{PEMBAHASAN}

Stunting disebabkan oleh berbagai faktor. Penyebab anak stunting diantaranya tidak adekuatnya asupan zat gizi dan infeksi berulang serta penyakit kronis yang berlangsung pada seribu hari pertama kehidupan (Mahmudiono $\mathrm{T}$, Nindya T, 2016). Selain faktor tersebut, pola perawatan kesehatan, pola pengasuhan, ketersediaan dan akses pangan, dan karakteristik keluarga merupakan faktor yang juga berpengaruh terhadap kejadian stunting pada anak.

Hasil penelitian menunjukkan faktor penyebab stunting bagi ibu. Menurut patisipan (ibu), penyebab stunting adalah faktor keturunan, riwayat anak sulit atau pemilih makanan, riwayat kesehatan dan kondisi finansial keluarga. Beberapa penelitian sebelumnya menunjukan hasil yang sama dengan penelitian ini. Sebuah penelitian menunjukkan adanya hubungan antara faktor finansial dan kesehatan anak dengan kejadian stunting (Rahayuwati et al., 2019).

Sebagian besar informan pada penelitian ini menyatakan bahwa anak pendek (stunting) karena keturunan dari orang tua. Pernyataan informan ini menyebabkan orang tua yang memiliki anak stunting mengambil kesimpulan bahwa stunting tidak bisa dicegah atau diperbaiki. Berbagai penelitian sebelumnya telah dilakukan untuk membuktikan hubungan antara keturunan dengan kejadian stunting.

Penelitian lain menunjukkan tinggi badan ibu dan asupan sumber zinc berhubungan dengan stunting (Ramadhan, et al., 2020), faktor risiko lainnya yang menyebabkan terjadinya stunting adalah Berat Bayi Lahir Rendah (BBLR), usia ibu $>35$ tahun, tinggi badan ayah $<160 \mathrm{~cm}$ (Esfarjani, et al., 2013). Menurut Amin \& Julia (2016), faktor yang paling berpengaruh dengan stunting adalah tinggi badan ibu sedangkan tinggi badan ayah tidak menunjukkan hasil yang bermakna terhadap kejadian stunting (Amin \& Julia, 2016).

Beberapan penelitian lainya menunjukkan tidak ada hubungan antara tinggi badan orang tua (keturunan) dengan kejadian stunting pada balita. Menurut penelitian ini, faktor yang berhubungan dengan stunting yaitu pola asuh praktik pemberian makan dan perawatan kesehatan dengan kejadian stunting pada balita (Fadilah, et al., 2020). Literature review pada tahun 2019 menunjukkan bahwa keturunan bukanlah faktor risiko terjadinya stunting. Stunting berhubungan dengan panjang lahir (berisiko 16,43 kali), pendidikan ibu yang rendah (berisiko 3,27 kali), anak yang tinggal di desa (berisiko 2,45 kali), BBLR (berisiko 4,5 kali), tidak ANC (berisiko 3,4 kali), tidak imunisasi (berisiko 6,38 kali), dan tidak ASI Eksklusif (berisiko 4,0 kali) (Budiastutik \& Rahfiludin, 2019). 
Keturunan merupakan faktor yang menyebabkan stunting, tetapi bukan merupakan faktor dominan. Penelitian terdahulu menunjukkan faktor keturunan berperan hanya sebesar $15 \%$, penyebab utama stunting yaitu kurangnya asupan zat gizi, hormon pertumbuhan serta penyakit infeksi (Sari, et al., 2010). Dengan demikian masih banyak faktor yang bisa dikendalikan dan dicegah agar stunting tidak terjadi pada anak.

Persepsi informan yang menyatakan penyebab utama stunting adalah keturunan dipengaruhi oleh berbagai faktor. Diantaranya yaitu persepsi yang berkembang di masyarakat. Pandangan yang menganggap keturunan adalah faktor utama merupakan gambaran persepsi yang ada di masyarakat. masyarakat meyakini informasi bahwa faktor keturunan menentukan postur tubuh sehingga individu yang berbadan tinggi terlahir dari orang tua yang berbadan tinggi, dan sebaliknya. Persepsi ini menunjukkan pemahaman bahwa stunting disebabkan oleh faktor yang dibawa dari lahir, dan tidak bisa diubah. Fakta kesenjangan pemahaman ini memerlukan intervensi dari berbagai pihak agar dapat meluruskan persepsi masyarakat (Liem, et al., 2019).

Persepsi menggambarkan individu dalam menafsirkan pengalaman yang dialami. Rangsangan dalam hal ini infromasi yang diterima masyarakat tentang stunting akan membentuk suatu pemahaman atau cara pandang individu terhadap lingkungan kondisi stunting pada anak. Persepsi seseorang terhadap suatu hal yang sama, sangat mungkin berbeda dengan individu lainnya, karena melibatkan pola pengalaman sebelumnya. Persepsi berperan penting mempengaruhi perilaku karena berfungsi sebagai prediktor atau landasan dalam berperilaku. Kesalah pahaman tentang stunting disebabkan oleh faktor keturunan dapat menyebabkan orangtua anak bersikap pasif. Tanpa persepsi dan pemahaman yang akurat, akan sulit mengharapkan keterlibatan keluarga dalam program pemerintah mengatasi stunting. Dengan demikian, fokus intervensi pada keluarga sangat diperlukan sehingga nantinya dapat berkembang persepsi yang benar di masyarakat.

Faktor selanjutnya yang mempengaruhi stunting menurut informan yaitu finansial keluarga. Aridiyah 2015 menyatakan bahwa pendapatan keluarga mempengaruhi status nutrisi anak (Aridiyah, et al., 2015). Penelitian lainnya juga menunjukkan status sosial ekonomi mempengaruhi kondisi kesehatan anak (Alam, et al., 2020). Faktor finansial tidak terbatas pada kemampuan ekonomi keluarga tetapi juga salah satunya mencakup kualitas pelayanan Posyandu. Posyandu sebagai garda terdepan dalam mendeteksi stunting di masyarakat masih mengalami berbagai hambatan untuk memberikan pelayanan yang optimal di masyarakat. Hambatan keuangan, persediaan obat dan peralatan, serta lokasi pelaksanaan kegiatan posyandu yang terpencil di beberapa daerah masih menjadi kendala dalam pelaksanaan pelayanan yang optimal. Meskipun posyandu sudah diimplementasikan selama beberapa dekade, studi tersebut menemukan bahwa implementasinya belum optimal (Setiawan \& Christiani, 2018).

Masalah selanjutnya yaitu pola makan dan pola asuh, Masalah pemberian makan merupakan faktor yang berhubungan dengan kejadian stunting pada anak. Anak yang pemilih makanan (picky eater) akan berpotensi mengalami masalah kecukupan gizi. Picky eater adalah perilaku memilih-milih makanan yang ditandai dengan terbatasnya jumlah pilihan makanan. Picky eater menyebabkan orang tua harus menyediakan makan yang sesuai dengan keinginan anak. Hal ini memerlukan perhatian khusus agar orang tua mampu mengatasi picky eater pada anak usia dini. Penelitian lainnya menunjukkan kejadian picky eater pada anak prasekolah berakibat kekurangan asupan jangka panjang, sehingga dapat mengganggu pertumbuhan anak (Putri \& Muniroh, 2019).

Picky eater pada anak dapat dipengaruhi berbagai faktor. Hasil penelitian oleh Marlina menunjukkan bahwa ada hubungan antara pengetahuan ibu dengan kejadian picky eater pada anak usia pra sekolah (Marlina, et al., 2020). Pada penelitian ini sebagian besar ibu berpendidikan SMP yang dapat mempengaruhi kemampuan dalam mengatasi masalah picky eater pada anak. Namun, penelitian lainnya menunjukkan tidak ada hubungan yang bermakna antara kejadian stunting pada picky eaters balita dengan nilai $p$-value $=0,741 \quad(p$-value $>0,05)$ (Nugroho, 2020).

Berdasarkan hasil wawancara, sebagian besar informan menyatakan bahwa kader dan tenaga kesehatan dari Puskesmas setempat sering mengunjungi anak yang mengalami stunting dan memberikan tambahan makanan untuk anak. Akan tetapi, tidak dilakukan pemantauan efektifitas tambahan makanan yang diberikan. Beberapa informan menyatakan bahwa tambahan makanan berupa biskuit dan suplemen makanan yang diberikan tidak dikonsumsi oleh anak. Kondisi ini disebabkan karena anak menolak untuk mengkonsumsi makanan tersebut dan kadangkala dikonsumsi oleh saudaranya 
(umumnya kakak). Hal ini menunjukkan perlunya pemantauan dan pendampingan dalam mengatasi stunting pada anak. Pemantauan dan pendampingan pola makan dan cara pemberian makan yang tepat perlu dilakukan secara intensif. Agar upaya penyelesaian masalah dapat tepat sasaran.

Anak yang pemilih makanan (picky eater) akan berpotensi mengalami masalah kecukupan gizi. Picky eater adalah perilaku memilih-milih makanan yang ditandai dengan terbatasnya jumlah pilihan makana yang menyebabkan orang tua harus menyediakan makan yang sesuai dengan keinginan anak. Hal ini memerlukan perhatian khusus agar orang tua mampu memenuhi kebutuhan nutrisi anak (Adhani, 2019). Penelitian lainnya menunjukkan kejadian picky eater pada anak prasekolah berakibat kekurangan asupan jangka panjang, sehingga dapat mengganggu pertumbuhan anak (Putri \& Muniroh, 2019)

Masalah pemberian makan ini sangat berhubungan dengan pola asuh ibu sebagai pengasuh utama dalam keluarga. Beberapa penelitian menunjukkan pemberdayaan ibu selama proses perawatan anak dengan masalah gizi. Imai, Annim, Kulkarni, dan Gaiha menyatakan bahwa status nutrisi anak dapat ditingkatkan melalui pemberdayaan terhadap ibu sebagai pengasuh utama, meningkatkan status pendidikan ibu, dan meningkatkan akses terhadap pelayanan kesehatan (Imai, et al., 2014).

Ibu sebagai pengasuh utama seringkali menghadapi hambatan dalam merawat anaknya. Ibu mengeluhkan bahwa dirinya merasa malu membawa anaknya ke pelayanan kesehatan untuk mengatasi masalah gizi yang dialami anak. Ibu akan membawa anak ke pelayanan kesehatan hanya ketika anak mengalami penyakit penyerta (seperti ISPA, diare, demam, dan lain-lain). Sedangkan tenaga kesehatan menyatakan bahwa seringkali ibu yang memiliki anak dengan gizi buruk tidak memiliki motivasi yang tinggi untuk memperbaiki kondisi anak yang mengalami gizi buruk. Hal ini menyebabkkan ibu memerlukan pelatihan dan supervisi sehingga ibu menjadi percaya diri dalam merawat anak (Nahar, et al., 2012)

Salah satu upaya memperbaiki kesuliatan anak yaitu memahami konsep responsive feeding. Responsive feeding merupakan praktik pemberian makan yang diharapkan dapat mengatasi masalah pemberian makan pada anak. Banyak laporan dan penelitian tentang pentingnya penerapan responsive feeding dalam pemberian makan pada bayi dan anak. Responsive feeding dapat meningkatkan kemampuan self-feeding anak dan respon terhadap bahasa verbal ibu. Penelitian lain menunjukkan perkembangan anak menjadi lebih baik termasuk bahasa dan juga lebih pintar makan (mouthful eaten). Beberapa penelitian menganjurkan untuk memasukkan responsive feeding ke dalam kebijakan program peningkatan nutrisi anak. Tujuan akhir praktik pemberian makan pada anak adalah melatih anak untuk mengonsumsi makanan keluarga dan makan sendiri (self feeding). Selain itu melatih anak untuk berperilaku makan yang baik, disiplin, dan dapat menghargai makanan dan waktu makan (Sjarif, et al., 2014). Praktik Pemberian makan berbasis bukti sangat diperlukan untuk menjamin kecukupan nurtisi anak terutama pada 1000 HPK. Pola pemberian makan bayi dan batita dipengaruhi oleh pengalaman ibu, tuntutan keluarga, keadaan sosial ekonomi serta tradisi budaya (IDAI, 2015).

Faktor selanjutnya yaitu riwayat kesehatan anak. Status kesehatan dapat mempengaruhi kejadian stunting pada anak. Pada penelitian tahun 2015, riwayat penyakit infeksi yang dialami anak berhubungan dengan kejadian stunting pada anak balita yang berada di pedesaan maupun perkotaan dengan nilai $p$-value berturut-turut yaitu 0,017 dan $0,001<\alpha(0,05)$ (Aridiyah, et al., 2015). Selain itu, riwayat hospitalisasi juga mempengaruhi status gizi pada anak (Rahayuwati, et al., 2019). Pada penelitian ini menunjukkan bahwa salah satu penyebab stunting pada anak menurut informan yaitu riwayat hospitalisasi pada usia satu tahun pertama, riwayat lahir prematur dan berat lahir rendah.

Kondisi kesehatan anak dipengaruhi oleh asupan nutrisi bahkan ketika masih dalam kandungan. Dapat dilakukan berbagai upaya untuk mencegah terjadinya stunting, salah satunya memastikan nutrisi adekuat pada ibu hamil. Pemberian suplemen Fe, As.Folat, post natal IMD, ASI esklusif, MPASI 6-24 bln, stimulasi adekuat, pantau tumbang, dan imunisasi lengkap juga merupakan upaya untuk menjaga status kesehatan dalam kondisi optimal. Hasil Penelitian oleh Rahmayanti, et al. (2020), menunjukkan status nutrisi selama hamil berhubungan dengan kejadian stunting pada anak ( $p$-value $=0.000$. Anak yang dilahirkan dari ibu dengan intake nutrisi yang tidak adekuat 13 kali lebih besar berisiko memiliki anak yang stunting dibandingkan ibu hamil yang memperoleh nutrisi adekuat. Berdasarkan hal ini, pencegahan stunting dapat dilakukan semenjak ibu hamil (Fitriani, et al., 2020). Penelitian lainnya menunjukkan bahwa pemberian suplemen zat besi dan asam folat yang adekuat pada ibu hamil 
memiliki potensi untuk meningkatkan hasil pertumbuhan anak di Asia Selatan dan negaranegara berpenghasilan rendah dan menengah lainnya dengan tingkat kekurangan zat besi yang tinggi pada kehamilan. Suplementasi zat besi dan asam folat pada empat bulan pertama kehamilan berkaitan dengan penurunan risiko stunting, stunting berat, dan berat bayi lahir rendah (BBLR) (Nisar, et al., 2020).

Komponen utama pencegahan stunting meliputi pola asuh/parenting yang optimal, pola makan yang baik, sanitasi yang terjaga dan pencegahan penyakit/infeksi. Upaya ini harus diikuti dengan perubahan kebiasan dan persepsi yang benar di masyarakat. Pola pembentukan persepsi yang benar akan meningkatkan kerjasama masyarakat dalam upaya pencegahan dan penanganan stunting yang terjadi di Indonesia.

\section{DAFTAR PUSTAKA}

Adhani, D. N. (2019). Peran Orang Tua terhadap anak usia dini (usia 2 tahun) yang mengalami Picky Eater. Aulad: Journal on Early Childhood, 2(1), 39-44.

Alam, M. A., Richard, S. A., Fahim, S. M., Mahfuz, M., Nahar, B., Das, S., Shrestha, B., Koshy, B., Mduma, E., Seidman, J. C., Murray-Kolb, L. E., Caulfield, L. E., \& Ahmed, T. (2020). Impact of Early-Onset Persistent Stunting on Cognitive Development at 5 Years Of Age: Results From A Multi-Country Cohort Study. PloS one, 15(1), $\mathrm{e} 0227839$. https://doi.org/10.1371/journal.pone.02278 39

Amin, N. A., \& Julia, M. (2016). Faktor Sosiodemografi dan Tinggi Badan Orang Tua Serta Hubungannya Dengan Kejadian Stunting Pada Balita Usia 6-23 Bulan. Jurnal Gizi Dan Dietetik Indonesia (Indonesian Journal of Nutrition and Dietetics).

https://doi.org/10.21927/ijnd.2014.2(3).17 $0-177$

Aridiyah, F., Rohmawati, N., \& Ririanty, M. (2015). Faktor-faktor yang Mempengaruhi Kejadian Stunting pada Anak Balita di Wilayah Pedesaan dan Perkotaan (The Factors Affecting Stunting on Toddlers in Rural and Urban Areas). Pustaka Kesehatan, 3(1), 163-170. Retrieved

\section{SIMPULAN}

Penelitian ini menghasilkan salah satu tema yaitu penyebab stunting menurut perspektif ibu. Tema terdiri atas kategori keturunan, anak sulit/pemilih makanan, kondisi kesehatan anak, dan kondisi finansial. Sebagian besar informan meyakini bahwa factor keturunan adalah penyebab terjadinya stunting. Berdasarakan pembahasan, faktor keturunan dapat mempengaruhi kejadian stunting pada anak tetapi tidak merupakan determinan utama. Terdapat faktor lainnya yang menyebabkan stunting pada anak.

Ibu memerlukan konseling dan supervisi untuk meningkatkan pengetahuan dan kemampuan dalam merawat anak khususnya dalam memenuhi kebutuhan nutrisi. Kesenjangan pengetahuan tentang stunting memerlukan upaya menjembatani hasil penelitian-penelitian yang dilakukan dan upaya promosi kesehatan yang adekuat di masyarakat.

from https://jurnal.unej.ac.id/index.php/JP K/article/view/2520

Bowden, V. R., \& Greenberg, C. S. (2010). Children and their families: The continuum of care (2nd ed.). Philadelphia: Williams \& Wilkins.

Budiastutik, I., \& Rahfiludin, M. Z. (2019). Faktor Risiko Stunting Pada Anak Di Negara Berkembang. Amerta Nutrition. 2(3), 122-126 https://doi.org/10.20473/amnt.v3i3.2019.1 22-129

Darnton-Hill, M. U. (2015). Micronutrients in Pregnancy in Low- and Middle-Income Countries. Nutrients, 7, 1744-1768.

Dinas Kesehatan Kabupaten Banyumas. (2018). Profil Kesehatan Kabupaten Banyumas tahun 2017. Purwokerto, 2018. Epub ahead of print 2018. DOI: 10.1016/j.jim.2005.11.005. https://doi.org/10.1016/j.jim.2005.11.005

Esfarjani, F., Roustaee, R., Mohammadi, F., \& Esmaillzadeh, A. (2013). Determinants Of Stunting In School-Aged Children Of Tehran, Iran. International journal of preventive medicine, 4(2), 173-179.

Fadilah, S. N. N., Ningtyias, F. W., \& Sulistiyani, S. (2020). Tinggi Badan Orang Tua, Pola Asuh Dan Kejadian Diare Sebagai Faktor Risiko Kejadian Stunting Pada Balita Di Kabupaten Bondowoso. Ilmu Gizi 
Indonesia. $\quad 4(1) \quad 2020, \quad 11-18$ https://doi.org/10.35842/ilgi.v4i1.148

Fitriani, H., R, A. S., \& Nurdiana, P. (2020). Risk Factors of Maternal Nutrition Status During Pregnancy to Stunting in Toddlers Aged 12-59 Months. Jurnal Keperawatan Padjadjaran, 8(2), 183-191. https://doi.org/10.24198/jkp.v8i2.1305

IDAI. (2015). Rekomendasi Praktik Pemberian Makan Berbasis Bukti pada Bayi dan Batita di Indonesia untuk Mencegah Malnutrisi. UKK Nutrisi Dan Penyakit Metabolik, Ikatan Dokter Anak Indonesia. https://doi.org/10.1017/CBO97811074153 24.004

Imai, K. S., Annim, S. K., Kulkarni, V. S., \& Gaiha, R. (2014). Women's Empowerment and Prevalence of Stunted and Underweight Children in Rural India. World Development, 62,88-105. https://doi.org/10.1016/j.worlddev.2014.05 .001

Kusrini, I., \& Laksono, A. D. (2020). Regional Disparities of Stunted Toddler in Indonesia. Indian Journal of Forensic Medicine and Toxicology. 7(9), 61156121. https://doi.org/10.31227/osf.io/6zqdc

Liem, S., Panggabean, H., \& Farady, R. M. (2019). Persepsi Sosial Tentang Stunting di Kabupaten Tangerang. Jurnal Ekologi Kesehatan. 8(1),37-47

https://doi.org/10.22435/jek.18.1.167.37-47

Mahmudiono T, Nindya T, A. D. (2016). The Effectiveness of Nutrition Education for Overweight/Obese Mothers with Stunted Children (NEO-MOM) in Reducing the Double Burden of Malnutrition in Indonesia: Study Protocol for a Randomized Controlled Trial. BMC Public Health, 16, 486.

Marlina, H., Rany, N., Rosalina, L., Faridah, A., \& Permaisuri, I. (2020). Risk Factors For Picky Eater In Preschool Children In AnNamiroh Kindergarten, Psekanbaru City. International Journal of Scientific and Technology Research, 9(4), 17--174

Nahar, B., Hossain, M.I., Hamadani, J.D. et al. Effects Of Psychosocial Stimulation On Improving Home Environment And ChildRearing Practices: Results From A Community-Based Trial Among Severely Malnourished Children In Bangladesh. BMC Public Health 12, 622 (2012). https://doi.org/10.1186/1471-2458$12-622$

Nisar, Y. B., Aguayo, V. M., Billah, S. M., \& Dibley, M. J. (2020). Antenatal Iron-Folic
Acid Supplementation Is Associated with Improved Linear Growth and Reduced Risk of Stunting or Severe Stunting in South Asian Children Less than Two Years of Age: A Pooled Analysis from Seven Countries. Nutrients, 12(9), 2632. https://doi.org/10.3390/nu12092632

Nugroho, A. (2020). History of Breastfeeding, Formula and Eating Patterns in Stunted Toddlers: The Case With Picky Eaters. International Journal of Innovation, Creativity and Change.

Paciorek CJ, Stevens GA, Finucane MM, et al. (2013). Children's Height and Weight in Rural and Urban Populations in LowIncome and Middle-Income Countries: A Systematic Analysis of PopulationRepresentative Data. Lancet Glob Heal 2013; 1:, 1, e300-e309.

Putri, A. N., \& Muniroh, L. (2019). Hubungan Perilaku Picky Eater dengan Tingkat Kecukupan Zat Gizi dan Status Gizi Anak Usia Prasekolah Di Gayungsari. Amerta Nutrition. 3(4), 232-238. https://doi.org/10.20473/amnt.v3i4.2019.2 32-238

Rahayuwati, L., Nurhidayah, I., Hidayati, N. O., Hendrawati, S., Agustina, H. S., \& Ekawati, R. (2019). Analysis of Factor Affecting Nutrition Status on Children. Jurnal Keperawatan Padjadjaran. 7(2), 117-131 https://doi.org/10.24198/jkp.v7i2.1131

Rahmayanti, S. D., Dewi, S., \& Fitriani, H. (2020). HUBUNGAN PENGETAHUAN DAN SIKAP IBU TENTANG GIZI DENGAN KEJADIAN STUNTING PADA ANAK USIA 2-4 TAHUN DI RW 04 DAN RW 07 KELURAHAN CIGUGUR TENGAH. Jurnal Kesehatan Kartika, 15(2), 15-24.

Ramadhan, M. H., Salawati, L., \& Yusuf, S. (2020). Hubungan Tinggi Badan Ibu, Sosial Ekonomi dan Asupan Sumber Zinc dengan Kejadian Stunting Pada Anak Usia 3-5 Tahun di Puskesmas Kopelma Darussalam. 6 (1),55-65 Averrous: Jurnal Kedokteran Dan Kesehatan Malikussaleh. https://doi.org/10.29103/averrous.v6i1.262 8

Sari, M., De Pee, S., Bloem, M. W., Sun, K., Thorne-Lyman, A. L., Moench-Pfanner, R., Akhter, N., Kraemer, K., \& Semba, R. D. (2010). Higher Household Expenditure on Animal-Source and Nongrain Foods Lowers The Risk of Stunting Among Children 0-59 Months Old in Indonesia: 
Implications of Rising Food Prices. Journal of Nutrition. 140 (1),195-200 https://doi.org/10.3945/jn.109.110858

Setiawan, A., \& Christiani, Y. (2018). Integrated Health Post for Child Health (Posyandu) As A Community-Based Program in Indonesia: An Exploratory Study. Jurnal Keperawatan Indonesia, 21(3),150-158 https://doi.org/10.7454/jki.v21i3.600

Sjarif, D. R., Yuliarti, K., Sembiring, T., Lubis, G., Anzar, J., Prawitasari, T., Lestari, E.
D., Mexitalia, M., Nurani, N., Widjaja, N. A., Puryatni, A., Sidiartha, I. G. L., \& Baso, A. J. (2014). Rekomendasi Ikatan Dokter Anak Indonesia Pendekatan Diagnosis dan Tata Laksana Masalah Makan pada Batita di Indonesia. http://spesialis1.ika.fk.unair.ac.id/wpcontent/uploads/2017/03/RekomendasiPendekatan-Diagnosis-dan-Tata-LaksanaMasalah-Makan-Pada-Batita.pdf 